\title{
Less is more: Video Assisted Thoracoscopic (VATS) Lobectomy vs Thoracotomy- a Clinical and Cost Analysis in a Developing Country
}

Nur Aziah Ismail*, Nurul Hafizah Zailani, Sing Yang Soon

Sarawak Heart Centre, Kuching Samarahan expressway 94300 Kota Samarahan, Sarawak Malaysia

DOI: $10.36347 /$ sjams.2020.v08i05.037

| Received: 05.05.2020 | Accepted: 20.05.2020 | Published: 30.05 .2020

*Corresponding author: Nur Aziah Ismail

Introduction: Video assisted thoracoscopy (VATS) lobectomy has become a standard approach in the management of patients with lung cancer, more so in the recent years. As many literatures has claimed benefits of VATS over thoracotomy in terms of clinical settings, it is also equally important to evaluate whether these benefits translate into cost implications. Objectives: The aim of this study is to investigate the postoperative complications and mortality following VATS lobectomy compared to Open lobectomy and to evaluate whether these clinical implications could translate into cost effectiveness. Materials and methods: A retrospective study of all patients who underwent lobectomy performed by a single surgeon between the year 2014 to 2019 was conducted. Data was obtained through patient's medical notes. Results: A total of 81 patients underwent lobectomy under a single surgeon (VATS n= 39, Thoracotomy $\mathrm{n}=42$ ). Patients demographics were similar in both groups. Operating time were also similar in both groups. Epidural requirement (hours) were significantly shorter in VATS group $(34.8 \pm 19.8$ vs $55.6 \pm 17.9$, p<0.001) There were more blood loss in Thoracotomy group $(1.4 \pm 0.8 \mathrm{~g} / \mathrm{dl}$ vs $1.0 \pm 0.5 \mathrm{~g} / \mathrm{dl}, \mathrm{p}=0.044)$. Chest tube days were significantly shorter in the VATS group $(4.8 \pm 3$.8days vs. $7.6 \pm 9.2$ days, $\mathrm{p}=0.01)$ and so was length of stay $(6.8 \pm 4.0$ days vs. $8.9 \pm 5.9$ days $\mathrm{p}=0.026$ ). There were no $<30$ days mortality in both groups. $>90$ days mortality were similar in both groups $(21.4 \%$ vs $15.4 \%, \mathrm{p}=0.484)$. Total cost of stay was higher in the Thoracotomy group (RM10,488 $\pm 4,436$ vs. RM9205 \pm 4420, p=0.196). Conclusions: Lobectomy performed via VATS approach results in less epidural requirement, shorter chest tube duration, less blood loss, shorter hospital stay. Shorter duration of hospital stay translates into less cost for the patient and hospital.

Keywords: Video assisted thoracoscopy (VATS), thoracotomy, lobectomy, blood loss.

Copyright @ 2020: This is an open-access article distributed under the terms of the Creative Commons Attribution license which permits unrestricted use, distribution, and reproduction in any medium for non-commercial use (NonCommercial, or CC-BY-NC) provided the original author and source are credited.

\section{INTRODUCTION}

Video assisted thoracoscopy (VATS) lobectomy has become a standard approach in the management of patients with lung cancer, especially more so in the recent years. Although there is a growing number of surgeons adopting this minimally invasive technique, some are still reluctant, perhaps due to the initial learning curve and lack of high-level evidence. Many literatures have claimed the benefits of VATS over thoracotomy in terms of post-operative pain, pulmonary function, post-operative complication and shorter hospital stay. In the current economical climate, it is also equally important to evaluate whether these benefits translate into cost implications.

\section{OBJECTIVE}

In this study we aim to:

1. Investigate the postoperative complications and mortality following VATS lobectomy compared to thoracotomy approach.
2. To evaluate whether these clinical implications could translate into cost effectiveness.

\section{MeTHODS}

A retrospective study was conducted out for all the patients who underwent lobectomy via VATS and thoracotomy under a single surgeon in our centre between the year 2014 to 2019. Pre-operative, operative and post-operative data were obtained from the patients' medical records. Patients were all followed up in outpatient clinic after discharge from the unit. Patients with concomitant chest wall resection were excluded.

\section{RESULTS}

A total of 81 patients were identified. $92.6 \%$ of these patients underwent lobectomy for Non-Small Cell Lung Cancer (NSCLC), 3.7\% had Carcinoid tumour, $2.5 \%$ had TB with aspergillosis, $1.2 \%$ had Sclerosing pneumocytoma and $1.2 \%$ had Necrotising Pneumonia. 
42 patients $(41.9 \%)$ had Thoracotomy and 39 patients $(48.1 \%)$ had VATS. Mean age for both groups were similar $59.2 \pm 15.1$ for thoracotomy group and 62.6 \pm 12.9 for VATS group $(\mathrm{p}=0.374)$. The number of patients with NSCLC for both groups were also similar $37(88.1 \%)$ for Thoracotomy group and $38(90.5 \%)$ for VATS group, $\mathrm{p}=0.724$. Operative time was noted to be longer for the thoracotomy group at $287.6 \pm 99.7$ minutes versus $257.2 \pm 59.8$ minutes for VATS $(\mathrm{p}=0.01)$. There was no intraoperative mortality.

Post-operatively, the thoracotomy group was noted to require significantly longer period of epidural compared to the VATS group 55.6 \pm 17 .9hours vs $34.8 \pm 19.8$ hours $(p<0.001)$. Total opioids consumed post-operatively were more for the thoracotomy group at $55.8 \pm 68 \mathrm{mg}$ compared to $44.3 \pm 47.5 \mathrm{mg}$, although this was not statistically significant $(\mathrm{p}=0.273)$. Blood loss were lower in the VATS group compared to the thoracotomy group: median of $0.9 \mathrm{~g} / \mathrm{dl}$ vs $1.4 \mathrm{~g} / \mathrm{dl}$, $\mathrm{p}=0.04$. Only one patient $(2.6 \%)$ in the VATS group required blood transfusion, compared to $4(9.5 \%)$ in the thoracotomy group.
Duration of chest tube were also significantly shorter in the VATS group $4.8 \pm 3.8$ days vs 7.6 \pm 9.2 days $(p=0.01)$. There was no wound infection in the VATS group compared to 3 in the thoracotomy group. Post-operative pneumonia was $17.9 \%$ in the VATS group and $28.6 \%$ in the thoracotomy group $(p=0.26)$. Total length of ICU stay were similar for both groups $2.4 \pm 1.2$ days for thoracotomy and $2.3 \pm 1.2$ days for VATS respectively, $p=0.063$. Length of ward stay were shorter for the VATS group at $4.6 \pm 3.5$ days vs $6.6 \pm 5.9$ days, $\mathrm{p}=0.07$. Thoracotomy group had a longer total hospital stay at $8.9 \pm 5.9$ days vs $6.8 \pm 4.0$ days for the VATS group, $\mathrm{p}=0.026$. There were two readmission for the thoracotomy group and one for VATS group. Reasons for readmission were pneumonia and pneumothorax requiring chest drain insertion.

There were no <30 day mortality for both groups. Kaplan Meier analysis of five year follow up revealed no statistically significant difference in mortality for both groups at five year post-op (See Table-1).

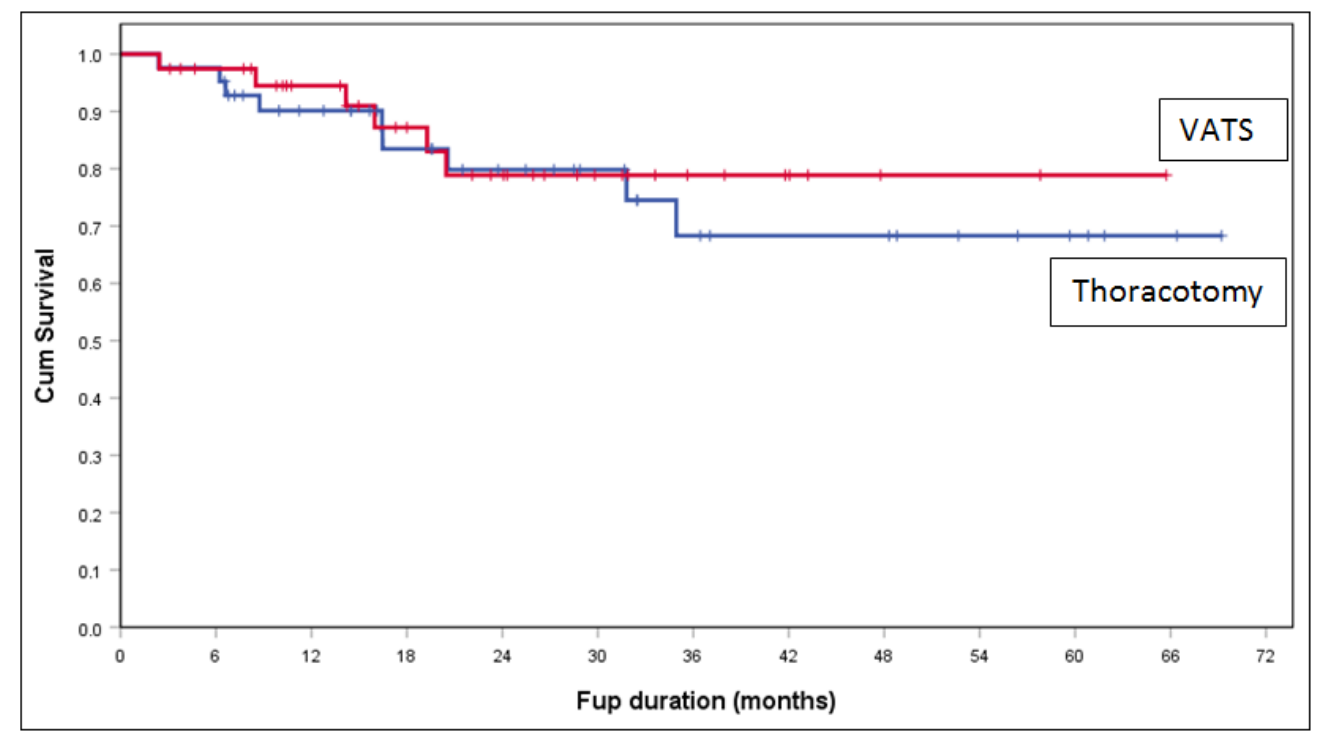

With regards to total length of stay (LOS) cost, mean total LOS cost is cheaper for VATS RM9,205 $\pm 4,420$ compared to RM 10,488 $\pm 4,436$.

\section{Study Limitations}

This study is a retrospective study with a small sample size. Comparisons between the two groups were not adjusted for case mix or tumour staging. There is also a variation in the study population itself whereby the access to outpatient clinic and healthcare may be difficult due to geographical and financial reasons.

\section{DISCUSSION}

Throughout the years, thoracic surgery has witnessed the evolution of approach to lobectomy- from the traditional thoracotomy to the three port VATS, two port VATS and in recent years uniportal VATS. VATS lobectomy is now considered the standard approach in the management of patients with lung cancer. Many series in the literature have shown superiority of VATS over thoracotomy for lung resection, as well as facilitating adjuvant chemotherapy post-operatively [1$6]$. The largest multi- centre randomized control trial study to date on VATS versus Open lobectomy is the Violet Study. In this RCT, the VATS group showed less post-operative pain, a shorter hospital stay and a $26 \%$ reduction in post-operative complications [7]. Our study similarly found a shorter LOS for the VATS group at 6.8 days vs 8.9 days for the thoracotomy group. The shorter hospital stay with VATS lobectomy were also confirmed by Falcoz et al who found a two days shorter 
hospital stay in the VATS group in a propensity matched analysis of the European Society of Thoracic Surgeon (ESTS) database of 2721 patients [8].

Post-operative pain was noted to be less in the VATS group in our study which was reflected by the significantly reduced amount of epidural requirement in the VATS group. Our study did not show much difference in the amount of oral analgesia consumed between the two groups. This could be due to the fact that a fixed amount of oral analgesia was prescribed routinely for all the cases rather than on a request basis. A randomized controlled trial conducted by Bendixen $e t$ al., looked at post-operative pain and quality of life between the vats and thoracotomy showed that a significantly greater number of thoracotomy patients were in clinically relevant pain in the first 24 hours after operation [9]. They have concluded that VATS is associated with less post-operative pain and better quality of life compared to thoracotomy for the first year after surgery.

This study has also found a shorter chest tube duration in the VATS group compared to thoracotomy group, $4.8 \pm 3.8$ days vs $7.6 \pm 9.2$ days respectively. This may have contributed to the shorter length of stay of patients in the VATS group. A propensity matched analysis of 963 cases conducted by Stephens et al., showed a shorter chest tube duration in the VATS group compared to thoracotomy - median of 2 days vs 3 days which is comparable to our results of median 4 days vs 4.5 days [10]. They similarly found a shorter LOS with the VATS group median 4 days vs 6 days. Our median LOS was 6 days in the VATS group and 7 days in the thoracotomy group. Our slightly longer LOS and chest tube days could have been contributed by the fact that our populations were mainly from the rural areas with limited access to healthcare and therefore threshold for discharge from the hospital is higher than one would normally expect.

Blood loss and requirement for blood transfusion were notably less in the VATS group. Median $\mathrm{Hb}$ drop in the VATS group were $0.9 \mathrm{~g} / \mathrm{dl}$ compared to $1.4 \mathrm{~g} / \mathrm{dl}$ in the thoracotomy group. Only one patient required blood transfusion in the VATS group as opposed to four in the thoracotomy group. AlAmeri et al., in his Swedish nationwide cohort study also found a significantly higher number of blood transfusions in the thoracotomy group 5\% vs $1.4 \%$ [11]. This finding was further confirmed by a randomized study done by Long et al who found a significantly less intraoperative blood loss in the VATS group [12]. They also noted a shorter operating time in the VATS group. Similarly, our median operating time for VATS was much less than thoracotomy. Although it could be argued that a longer operating time in the thoracotomy group could be due to the more complex disease in the thoracotomy group.
In our centre the operation cost for thoracotomy and VATS were the same. However, the length of stay cost were variable from patient to patient. We found the mean cost of hospital stay for vats to be cheaper than thoracotomy (RM 9,205 vs RM 10, 488). This goes hand in hand with the findings of Casali et $a l$, who concluded that the final cost of VATS lobectomy is less than conventional thoracotomy due to the shorter hospital stay [13]. This was further supported by Ramos et al in France who also found that the increased theatre costs in the VATS group were counteracted by the shorter hospital stay, bringing the total cost down to less than the thoracotomy group [14]. This cost could further be brought down with the implementation of Enhanced Recovery after Surgery program (ERAS) which could be beneficial for both health provider and patients.

\section{CONCLUSION}

Our study shows that VATS lobectomy is associated with less blood loss, less epidural requirement, shorter chest tube days and length of hospital stay. Reduced length of hospital translates into less cost for healthcare providers and patients.

\section{REFERENCES}

1. Daniels LJ, Balderson SS, Onaitis MW, D'Amico TA. Thoracoscopic lobectomy: a safe and effective strategy for patients with stage I lung cancer. Ann Thorac Surg, 2002; 74:860-4.

2. Hoksch B, Ablassmaier B, Walter M, Muller JM. Complica- tion rate after thoracoscopic and conventional lobectomy. Zentralblatt fur Chirurgie, 2003;128:106-10.

3. Nomori $H$, Ohtsuka $T$, Horio $H$, Naruke $T$, Suemasu K. Difference in the impairment of vital capacity and 6-minute walking after a lobectomy performed by thoracoscopic sur- gery, an anterior limited thoracotomy, an anteroaxillary thoracotomy, and a posterolateral thoracotomy. Surg Today, 2003;33:7-12.

4. Roviaro G, Varoli F, Vergani C, Nucca O, Maciocco M, Grignani F. Long-term survival after videothoracoscopic lobectomy for stage I lung cancer. Chest. 2004 Sep 1;126(3):725-32.

5. Ohtsuka $T$, Nomori $H$, Horio $H$, Naruke $T$, Suemasu K. Is major pulmonary resection by video-assisted thoracic sur- gery an adequate procedure in clinical stage I lung cancer? Chest, 2004;125:1742-6.

6. Petersen RP, Pham D, Burfeind WR, Hanish SI, Toloza EM, Harpole Jr DH, D'Amico TA. Thoracoscopic lobectomy facilitates the delivery of che- motherapy after resection for lung cancer. Ann Thorac Surg, 2007;83(4): 1245-9.

7. https://oncology.medicinematters.com/the-violetstudy/17041636

8. Falcoz PE, Puyraveau M, Thomas PA, Decaluwe H, Hürtgen M, Petersen RH, Hansen H, Brunelli 
A, ESTS Database Committee and ESTS Minimally Invasive Interest Group, Brunelli A, Raemdonck DV. Video-assisted thoracoscopic surgery versus open lobectomy for primary nonsmall-cell lung cancer: a propensity-matched analysis of outcome from the European Society of Thoracic Surgeon database. Eur Journal Cardiothorac Surg, 2016;49:602-9.

9. Bendixen $\mathrm{M}$, Jorgensen $\mathrm{OD}$, Kronborg $\mathrm{C}$, Andersen C, Licht PB. Postoperative pain and quality of life after lobectomy via video-assisted thoracoscopic surgery or anterolateral thoracotomy for early stage lung cancer: a randomised controlled trial. The Lancet Oncology, 2016, 17(6):836-844

10. Stephens N, Rice D, Correa A, Hoffstetter W, Mehran R, Roth J, Walsh G, Vaporciyan A, Swisher S. Thoracoscopic lobectomy is associated with improved short-term and equivalent oncological outcomes compared with open lobectomy for clinical Stage I non-small-cell lung cancer: a propensity-matched analysis of 963 cases. European Journal of Cardio-Thoracic Surgery. 2014 Oct 1;46(4):607-13.

11. Al-Ameri M, Bergman P, Franco-Cereceda A, Sartipy U. Video-assisted thoracoscopic versus open thoracotomy lobectomy: a Swedish nationwide cohort study. Journal of thoracic disease. 2018 Jun;10(6):3499- 3506.

12. Long H, Tan Q, Luo Q, Wang Z, Jiang G, Situ D, Lin Y, Su X, Liu Q, Rong T. Thoracoscopic surgery versus thoracotomy for lung cancer: shortterm outcomes of a randomized trial. The Annals of thoracic surgery. 2018 Feb 1;105(2):386-92.

13. Casali G, Walker WS. Video-assisted thoracic surgery lobectomy: can we afford it?. Eur Journal Cardiothorac Surg. 2009;35(3):423- 428.

14. Ramos R, Masuet C, Gossot D. Lobectomy for early-stage lung carcinoma: a cost analysis of full thoracoscopy versus posterolateral thoracotomy. Surg Endosc. 2012;26(2):431- 437. 